\title{
Digital Literacy of Students Using R Language
}

\author{
Rahma Wahyu' ${ }^{1}$, Sinollah $^{2}$ \\ \{rahmawahyu7@gmail.com\} \\ Universitas Islam Raden Rahmat, Jl. Raya Morjosari 2, Malang, Indonesia
}

\begin{abstract}
This study aims to develop an integrated management statistics textbook with R language to improve the digital literacy of students. Managements Statistics getting to know primarily based totally on ICT required to enhance it. Using packages is a high-quality manner to recognize all statistical concepts. One of the packages that may be used is the $\mathrm{R}$ language. $\mathrm{R}$ is the software that may help process information, offer information in graphical form, and study information. Design research approach followed on this study. The textbook evolved with Plomp model and referred to Tessmer formative evaluation. The subject is the management students who took statistics subject. The findings display that the textbook is valid, practice, and effective from the content and construct aspects. The acquisition during this study, improving digital literacy using $\mathrm{R}$ language is $75 \%$ categorized.
\end{abstract}

Keywords: Managements Statistics, digital literacy, R language

\section{Introduction}

Statistics is a department of technology wished in each day lifestyles and so that people can't be separated from the usage of records itself. Statistics become the focus in mathematics education reformation as a critical factor of everyday lifestyles [1]. Statistics is a branch of mathematics that analyzes data collection, processing the data, analyzing the data, and making conclusions based on findings [2]. Statistics has a critical position in accomplishing studies and statistics processing correctly. Therefore, records wish to be mastered properly with the aid of using university students. Students are anticipated to recognize entire records through the Management Statistics class, describe the statistics, examine the statistics, and make conclusions.

Moreover, statistical evaluation is becoming common in training, economics, biology, et al.. Because the need for statistics collection will increase, students are anticipated to enhance their potential to apply for the software program to process, present, and read statistics in graphical form. Nowadays, many software or programs have been developed that can help us in processing, presenting, and analyzing data in graphic form. Among the available software, some of them are free and paid software. 
$\mathrm{R}$ is a free version of S language from a kind of paid software, namely S-PLUS [4]. $\mathrm{R}$ has entire and dependable functions that could help us process, present, and read statistics in the graphical form [5]. Furthermore, moral and legal responsibility factors are no longer becoming a concern in using $\mathrm{R}$ because they can be obtained freely. There are several reasons why $\mathrm{R}$ is used, including $\mathrm{R}$ is a language programming, so there are no restrictions for users to use procedures that can only be found in standard packages [5].

Analyzing data requires interactive operations. $\mathrm{R}$ is equipped with connectivity to the server database, and $\mathrm{R}$ is almost entirely compatible with the S-Plus [4]. Most of the code created by $\mathrm{S}$ can be run in S-Plus except for the add-on packages functions or addition created by $\mathrm{R}$ project contributors. $\mathrm{R}$ is the most popular language programming used by researchers in the field of statistics. Several articles in the journal of statistics have proved this thing. $\mathrm{R}$ is likewise famous for quantitative utility inside the finance field. Students are predicted so that it will recognize the material in the Management Statistics subject completely. Their understandings are obtained from their independent study without expecting their lecturers to transfer all of the materials. This is caused by the lecturing process in colleges requires an independent effort from students so that the learning process will not be boring. However, there are still many students get the low score in statistics subject in UNIRA Malang. The percentage of students who score less than 65 (categories C, D, and E) is $73 \%$. This situation is still far from being expected.

The use of statistics has been applied in all sciences, but students' mastery has not been pleased, as explained [6]. Learning statistics are still taught traditionally, and transferring knowledge is still the mainstay method. Furthermore, learning knowledge should be connected to real life and explained its application [6]. Another case that often arises in Management Statistics lectures is the textbooks are still in translation version. It made the students feel not interested in learning the subject so that their ability to use their thinking skills to solve management statistics problems is low.

When viewed from the use of learning media, software in statistics subject in UNIRA Malang has not been implemented, even though there is much software such as $\mathrm{R}$ language. Using R language as Interactive learning media using ICT does have a significant contribution to learning among students and can support interactions with other people [3, 7-8]. R's utilization of functions and packages will create an animation program to demonstrate a theoretical theory $[9,10]$. With a suitable preference of media or gaining knowledge of resources, it may affect students' capacity to have interaction in gaining knowledge via interplay with the media [9]. So expect, using R language can improve digital literacy and benefit students looking to develop computer skills for their careers [11]. Digital literacy is one of the six basic literacy, which is applied, especially in learning activities. Digital literacy can be grown by using the software in learning. Based on the description above, it is necessary to develop a Management Statistics textbook accompanied by R software for students taking statistics subject in UNIRA Malang. The development of textbooks using $\mathrm{R}$ language is expected to improve the digital literacy of the students.

\section{Method}

The development approaches in this study use a model of design research [10] which includes three stages of preliminary research, prototyping phase, and assessment phase. In the Preliminary research phase, conducted problem and need analysis and literature study. The 
prototyping segment is creating a prototype. Assessment segment is the level of assessing whether or not the person can use a textbook (practicality) and wish to apply them and to assess the effectiveness of textbooks. Evaluation strategies used on this examine is a formative assessment that befell in all of the stages and the improvement cycle. The formative evaluation has numerous layers [11], as illustrated in Figure 1.

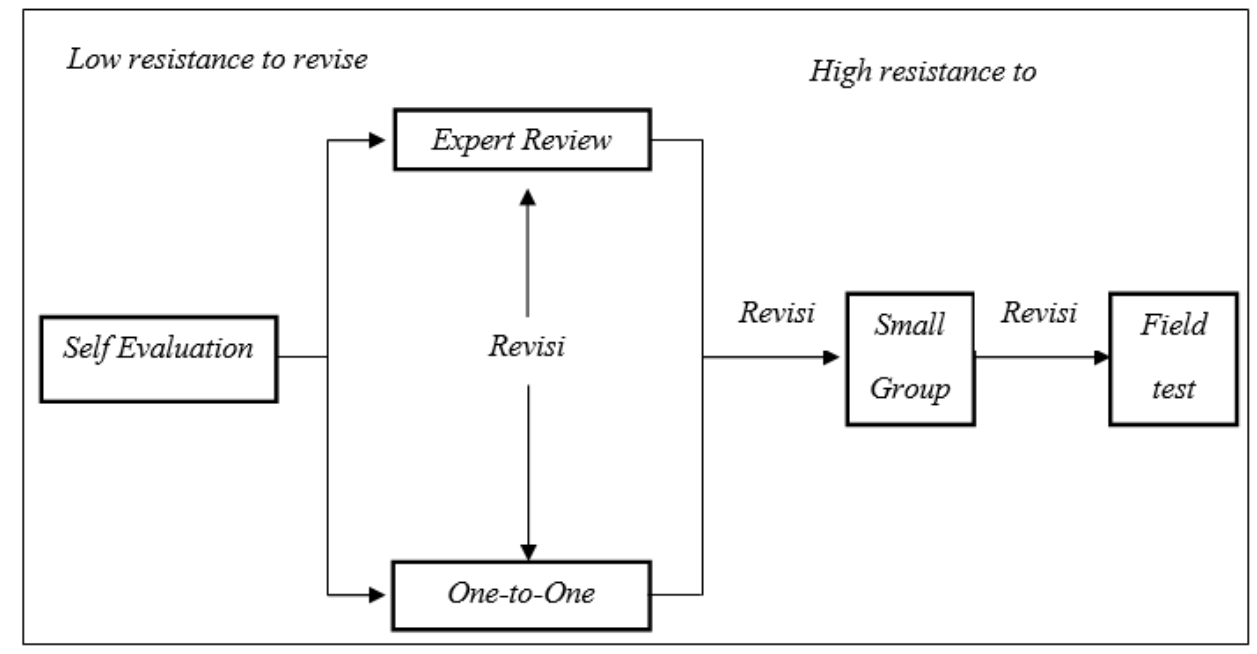

Fig.1. Flowchart of the evaluation process.

Figure 1 illustrates a number of the formative assessment techniques generally used. In this study, the formative assessment used is as follow: 1) Expert review. At this stage, the professional organization (a professional within side the area of study, professional educational layout) gives an evaluation and recommendation on the goods advanced; 2) Self-assessment is performed to apply checklists the crucial traits or layout specifications; 3). Evaluation of oneto-one (finished through customers who're consultant of instructors or college students); 4) Small organization or micro-assessment: related to small companies of college students through the use of the product in everyday situation. At this stage, the evaluator discovered and interviewed the respondents. Field take a look at changed into additionally finished to peer the effectiveness interactive textbook advanced and to get statistics to in addition enhancements to textbook advanced. The effectiveness of information accrued in pretest ratings and post-test a look at of college students. To see digital literacy skills, a questionnaire is used, the indicators of the questionnaire can be seen in table 1 .

Table 1. Student digital literacy indicator.

\begin{tabular}{cccc}
\hline No. & Item Indicator & Item Question & Total \\
\hline 1 & Benefit of technology & $1,2,3,4,5,6$ & 6 \\
\hline 2 & Using software & $7,8,9,10,11,12,13,14$, & 12 \\
\hline 3 & Social networking & $15,16,17,18$ & 4 \\
\hline 4 & Using learning media & $19,20,21,22$ & 4 \\
\hline 5 & Online Safety & $23,24,25,26$ & 2 \\
\hline 6 & Utilization digital literacy in learning & 27,28 & 2 \\
\hline
\end{tabular}




Total
Questions $\quad 30$

\section{Result and Discussion}

\subsection{Preliminary Phase}

Data of preliminary phase consequences acquired thru interviews with lecturer and students, syllabus document collection and learning implementation plan and statistics textbooks. Data acquired from the preliminary research namely interviews with the lecturer and students, and analyze the syllabus.

In the preliminary phase, showed that the responses acquired from lecturer do not forget that there need to be improvements in studying that enchantment to students in order that studying goals may be achieved. The responses acquired from the pattern students are interested by using ICT in studying. Student expectancies within side the utility of ICT isn't simplest constrained to using energy factor as a media presentation through the trainer however can get an exciting studying revel in and observe the improvement of technological know-how and technology. Experience in the usage of mathematical software program in studying records has by no means been acquired through lecturer. Implementation of ICT has ever accomplished simplest constrained to using energy factor as a media presentation. The use of this media is taken into consideration now no longer a lot help, in any other case even complicate the scholars in expertise the idea and the manner of calculation.

The second data from the preliminary research namely analyze the syllabus. The syllabus analyzed is the statistics syllabus. Based at the re-evaluation of the Statistics syllabus, the evolved textbook is designed textual content books that may be utilized in studying records for management.

\subsection{Prototyping Phase}

Developed prototype textbooks based on structures that have been designed. The activities for define step carried out at this stage are below: 1) Analyzing semester lesson plan (RPS), the purpose of this activity is to develop materials in the textbookwith $\mathrm{R}$ software in accordance with Learning Outcomes (CP) that must be achieved by students; 2) Analyzing Management Statistics textbook, to see the suitability of content in the textbook with the basic and standards competency that students must achieve; 3) Reviewing literatures related to the development of textbook, to see references for the textbooks; 4) Conducting interviews with lecturers and students, this aims to find out what problems or obstacles are faced in the field in relation with Management Statistics lecturing.

Based on the step above, the textbook is compiled which consists of four chapters which can be used for one semester, the parts are: 1) Basic concept of statistics; 2) Showing the data; 3) Descriptions; 4) Opportunity Theory. Each chapter contains a description of the material, sample of questions, exercises, and assignments. Each chapter consists of several learning activities that had been adjusted with syllabus. The structure that will be developed is as follows. 


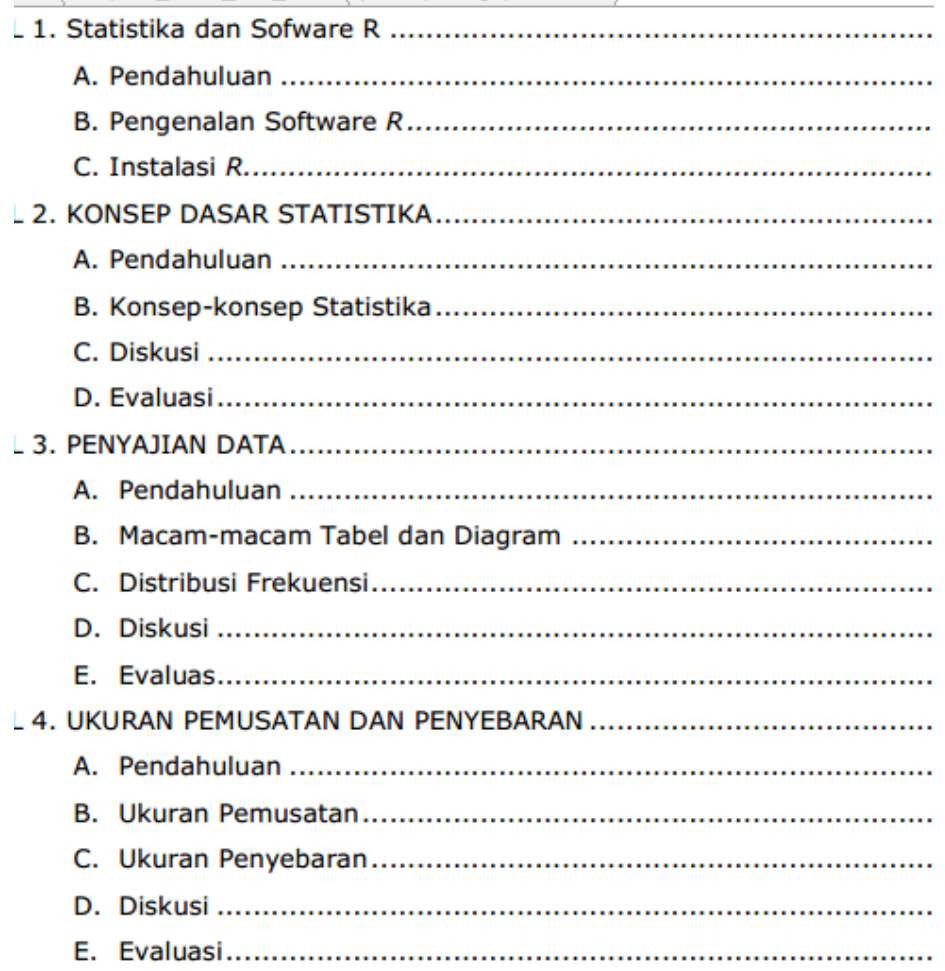

Fig.2. Structure of Text Book

The prototype of included R language in Management Statistics is primarily based totally systems which have been designed. Prototyping section is carried out following the formative assessment level evolved through Tessmer, this is making merchandise primarily based totally the consequences of the initial section analysis. Development is carried out through designing troubles and software program suitable to resolve the hassle presented. Software used is R language. The example of the textbook and textbook integrated $\mathrm{R}$ language can be seen in Figure 3. 

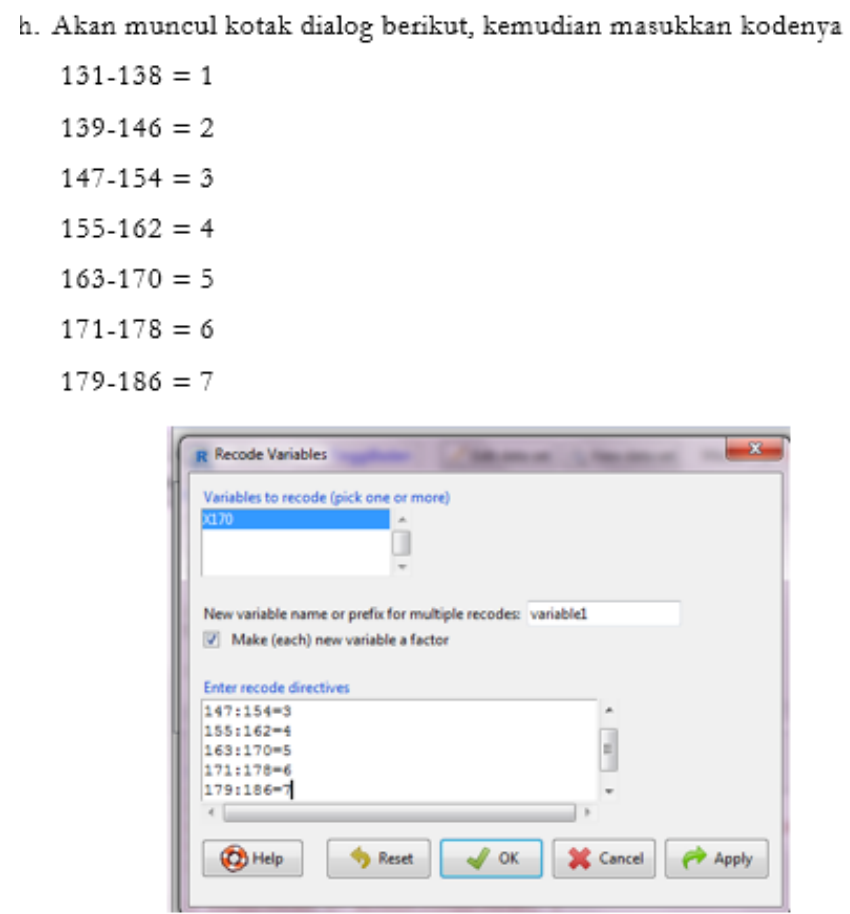

Fig. 3. Example of text book with R language

An expert review was conducted to evaluate the revised text book according to the results of self-evaluation. Results Validation by the lecturers for all aspects can be seen Table 2.

Table 2. Results Validation All Aspects

\begin{tabular}{lcc}
\hline & Aspects & Score \\
\hline Material/content & & $85.6 \%$ \\
Presentation & & $80.7 \%$ \\
Linguistics & $79.4 \%$ \\
Graphic & $81.3 \%$ \\
\hline Total & $81.75 \%$ \\
\hline
\end{tabular}

The four lectures' validation results indicated that the validity of statistics textbook in the criteria developed is very valid. The results of validation from the lectures as a whole is $81.75 \%$ by Muslich's opinion [12], which states that the textbook that has the content material feasibility is that if there's conformity of the cloth with the primary competence and competence supporters, material accuracy, and gaining knowledge of aid materials. The high-satisfactory of the textbook relies upon on its usefulness for gaining knowledge of functions university scholar. The extra wishes that may be served, the higher the book teach. For teachers, it presents possibilities for university students to examine in step with their very own speed; to do deepening; to make a revision and reflection; or document crucial matters for different functions.

Quality textbooks consequently now no longer handiest lie withinside the layout of the the book itself, however additionally on its usefulness. Good textbooks aren't only a series of ideas, however, programmed and systemic designs to paintings useful, concise but meaningful [13]. 
The end result of the textbook validation is visible from the content material, construct, linguistics, and image validity of the four components the assessed, acquired through class is pretty valid. It concluded that the version of era integration is needed for a powerful gaining knowledge of process [14]. Moreover, ICT helped students collect a closer knowledge of tunderstandingion material and enhance university students' achievement [15-17].

A follow-up of digital literacy to the $\mathrm{R}$ language is given to understand the result of university students' responses. It changed into acquired from the reactions of scholar questionnaires. The effects of the purchase of scholar responses withinside the use of textbooks with $\mathrm{R}$ language attain digital literacy responses, displaying a mean percent rating of $71.11 \%$. Achievement to hone digital literacy the usage of categorized educational media is especially on components of the advantage of the era, the usage of software, social networking, the usage of gaining knowledge of media, on-line Safety, usage of digital literacy in gaining knowledge of. In digital literacy, customers speedy make frameworks on present or proposed packages or different academic measures [18].

\section{Conclusion}

Related to the findings and evaluation of data, it can be concluded that textual content book for data challenge blanketed withinside the standards very valid. Learning included $\mathrm{R}$ language may be carried out as early as viable to equip digital literacy because it's far one of the 21-century abilities that should be owned through the contemporary learner. Integrated $\mathrm{R}$ language has been proven to positively impact university students' motivation and interest, which frequently consequences in elevated part and progressed behavior, even though it can't enhance mastering effects automatically [19-20].

Acknowledgments. The research team partner : Dr. M. Andy Rudhito \& Dr. rer.Nat. Herry Pribawanto Suryawan (FKIP-Universitas Sanata Dharma), DP2M Dikti, Universitas Islam Raden Rahmat, Malang, Indonesia

\section{References}

[1] Mavrotheris, M.m dan Mavrotheris, E, 2007. Online Communities of Practice Enhancing Statistics Instruction: the European Project Early Statitics. The Electronic Journal of e- learning. Vol 5, No 2:113-122.

[2] Sudjana. 1996. Metoda Statistika.Bandung: Transito

[3] Mujiyanto J and Rukmini D 2018 Students ' Perception on the Usefulness of ICT-Based Language Program 11.

[4] Alzola, C., and F. Harrell. 2006. An Introduction to S and The Hmisc and Design Libraries. http://biosfat.mc.vanderbilt.edu/RS.

[5] Ihaka Ross dan Robert Gentleman. 1996. R: A Language for Data Analysis and Graphics. Journal of Computational and Graphical Statistics. Volume 5. No. 3: 299-314.

[6] Leibman, Zipora. 2010. Integrating RealLife Data Analysis in Teaching Descriptive Statistics: A Constructivist Approach. Journal of Statistic Education. 18, (1). www.amstat.org/publications/jse/v 18n1/libman.p. 
[7] Zhang X and Maas Z 2019 Using R as a Simulation Tool in Teaching Introductory Statistics Int. Electron. J. Math. Educ. 14 599-610

[8] Delyana H, Rismen S and Handayani S 2018 Practicality of Elementary Statistics Module Based on CTL Completed by Instructions on Using Practicality of Elementary Statistics Module Based on CTL Completed by Instructions on Using Software R IOP Conf. Ser. Mater. Sci. Eng. 335 012122

[9] Watson D M 2001 Pedagogy before Technology: Re-thinking the Relationship between ICT and Teaching Educ. Inf. Technol. 6 251-66

[10] Plomp T 2013 "Educational Design Research an Introduction" in Tjeerd Plomp dan Nienke Nieveen (Eds.), Educational Design Research Part A: An Introduction (hlm. 9-35). Enschede: slo.

[11] Tessmer M 1993 Planning and Conducting Formative Evaluations (ebook) (Routledge: Taylor and Francis group).

[12] Muslich, Masnur. (2010). Text Book Writing. Jogjakarta: Ar-ruz Media.

[13] Kurniawan, Khaerudin. (2014). Handout Mata Kuliah Menulis Buku Ajar Ilmiah. file.upi.edu/Direktori/FPBS/JUR.../Handout_Buku_Ajar.pdf

[14] Altun S A, Kalayci E and Ümmühan A 2011 Integrating ICT at the faculty level: A case study Turkish Online Journal of Educational Technology 10(4), 230-240

[15] Cox M J and Marshall G 2007 Effects of ICT: do we know what we should know? Education and Information Technologies 12, 59-70

[16] Kulik C L C and Kulik J A 1991 Effectiveness of computer-based instruction: an updated analysisComputers in Human Behavior 7 75-94

[17] Cox M, Abbott C, Webb M, Blakeley B, Beauchamp T and Rhodes V 2003 ICT and attainment: A review of the research literature. ICT in Schools Research and Evaluation Series No.17. Coventry/London: Becta/DfES

[18] Martin A 2005 J. Elit. 2 130-136

[19] Smith H J, Higgins S, Wall K and Miller J 2005 Interactive whiteboards: Boon or bandwagon? A critical review of the literature J. Comput. Assist. Learn. 21 91-101

[20] Septia T, Rifai H and Cesaria A 2017 Interactive basic mathematics web using Wordpress J. Phys. Conf. Ser. 943 